Illinois State University

ISU ReD: Research and eData

Theses and Dissertations

4-14-2021

\title{
I Contain Multitudes: Identity Shift Effects of Diametrically Opposed Self-Presentations
}

Jacob John Valov

Illinois State University, jacobvalov@gmail.com

Follow this and additional works at: https://ir.library.illinoisstate.edu/etd

\section{Recommended Citation}

Valov, Jacob John, "I Contain Multitudes: Identity Shift Effects of Diametrically Opposed SelfPresentations" (2021). Theses and Dissertations. 1475.

https://ir.library.illinoisstate.edu/etd/1475

This Thesis is brought to you for free and open access by ISU ReD: Research and eData. It has been accepted for inclusion in Theses and Dissertations by an authorized administrator of ISU ReD: Research and eData. For more information, please contact ISUReD@ilstu.edu. 


\section{CONTAIN MULTITUDES: IDENTITY SHIFT EFFECTS OF DIAMETRICALLY \\ OPPOSED SELF-PRESENTATIONS}

\section{JACOB JOHN VALOV}

56 Pages

Identity shift theory suggests individuals who self-present through mediated channels see a change in their self-perception towards the qualities contained within said mediated selfpresentations. The present study sought to expand identity shift research through examining effects of multiple, diametrically opposed self-presentations in order to assess how individuals resolved potential cognitive dissonance caused by self-presentations dissimilar with an individual's extant self-presentations and to determine if identity shift effects occur across oppositional self-presentations. An experimental study $(N=54)$ asked participants to self-present diametrically opposed traits (conscientiousness/unconscientiousness) as opposed to one, singular trait, in order to assess resulting identity shift effects. Results demonstrated less-conscientious individuals experienced an identity shift towards being more conscientious, audience expectations did not affect identity shift, and strength of held self-belief did not moderate identity shift effects. These results suggest individuals may resist identity shifting towards negatively-valenced traits, audience evaluation may not affect identity shift when not presented as feedback, and mediated self-presentations may allow for greater psychological comfort when self-presenting oppositional traits as compared to face-to-face self-presentations.

KEYWORDS: identity shift, self-belief, context collapse, conscientiousness, media psychology 


\title{
I CONTAIN MULTITUDES: IDENTITY SHIFT EFFECTS OF DIAMETRICALLY OPPOSED SELF-PRESENTATIONS
}

JACOB JOHN VALOV

\author{
A Thesis Submitted in Partial \\ Fulfillment of the Requirements \\ for the Degree of \\ MASTER OF SCIENCE \\ School of Communication \\ ILLINOIS STATE UNIVERSITY
}


(C) 2021 Jacob John Valov 


\section{CONTAIN MULTITUDES: IDENTITY SHIFT EFFECTS OF DIAMETRICALLY OPPOSED SELF-PRESENTATIONS}

JACOB JOHN VALOV

COMMITTEE MEMBERS:

Caleb T. Carr, Chair

Phillip Chidester

John F. Hooker 


\section{ACKNOWLEDGMENTS}

I'd like to thank my friends, both near and far, for being the people who have held me together throughout my time at ISU. To Luis, Jared, Gabby, Maddie, MJ, and everyone else I've gotten to know here, I can't tell you how much you all mean to me and I look forward to knowing you all for the rest of my life. I'd like to thank my family - my parents, grandparents, aunts, uncles, and everyone in between. Your support has been amazing, and I couldn't have gotten as far as I have without you there to back me up. I'd also like to thank my friend Michael, who has been my invaluable go-to for grad student-related venting throughout my academic journey. I'd like to thank Dr. Phil Chidester and Dr. John Hooker for their tremendous help during this process and my two years at ISU. Phil, I'll always hold onto the memories of going to Buffalo Wild Wings with you and the long conversations about nothing we'd share in your office. Dr. Hooker, not only have you helped me grow as an instructor, but your help with this project's statistical analysis was invaluable. Lastly, I'd like to thank Dr. Caleb Carr. In between cracking wise in thesis meetings and combing through pages upon pages of edits, you showed me how to become the scholar I want to become. Your attitude of treating everyone around you as a scholar and as capable of creating incredible work has left a lasting impact on me, and that same belief in my work is what helped me get through this process despite everything that made this past year as difficult as it was. There are few compliments I'll cherish more than being told I remind people of you. 


\section{CONTENTS}

Page

ACKNOWLEDGMENTS

CONTENTS

ii

CHAPTER I: INTRODUCTION

CHAPTER II: REVIEW OF LITERATURE 3

Identity Shift 3

Mediated Self-Presentation $\quad 5$

Self-Presentation $\quad 5$

$\begin{array}{ll}\text { Mediation } & 6\end{array}$

$\begin{array}{ll}\text { Disentrainment } & 6\end{array}$

$\begin{array}{ll}\text { Deliberate Self-Presentation } & 7\end{array}$

$\begin{array}{lr}\text { Multiple Front Stage Selves } & 8\end{array}$

$\begin{array}{lr}\text { Strategic Online Self-Presentation } & 9\end{array}$

$\begin{array}{ll}\text { Context Collapse } & 10\end{array}$

LCD Audience Member $\quad 11$

$\begin{array}{ll}\text { Cognitive Dissonance } & 13\end{array}$

$\begin{array}{ll}\text { Boomerang Effect } & 13\end{array}$

$\begin{array}{ll}\text { Process Rationalization } & 16\end{array}$

$\begin{array}{ll}\text { Audience Expectations } & 19\end{array}$

$\begin{array}{ll}\text { Strength of Self-Belief } & 20\end{array}$

CHAPTER III: METHODS 22 
Self-Presented Trait

Procedures

Measures

Self-Belief Strength

Additional Measurements

CHAPTER IV: RESULTS

Hypotheses $1 \& 2$

Hypothesis 3

Hypothesis 4

Theoretical Implications

Trait Valence

Audience Expectations

Self-Belief

Practical Implications

Future Research

Conclusion 


\section{CHAPTER I: INTRODUCTION}

There is no universal self-presentation, particularly across different social media platforms. Different platforms host different audiences, and different audiences expect different behaviors from the same person. One person may adapt to being several different versions of themselves, as they naturally would be within different social circles, on different social media platforms. While these forms and bodies often overlap in their presentations of the self, as one is likely to consistently self-present with the foundational aspects of one's self-concept, there is often considerable difference between one person's multitude of self-presentations across platforms. On Twitter, one might feel comfortable presenting themselves as more vulnerable, potentially as someone dealing with depression or anxiety, whereas on Facebook, one may present themselves instead as highly successful and emotionally thriving. Both presentations may be rooted in real experiences and framings of one individual, but the self on Twitter and the self on Facebook could not appear more disparate, with only the physical body that they represent digitally tying them together.

These resultant variances in self-presentation, while potentially innocuous, can have effects on individuals' self-concepts. Previous research has explored the effects of selfpresentation through computer-mediated communication and found that by self-presenting as possessing a certain trait, individuals can experience a shift in their self-concept towards the trait they present (e.g., Walther, et al. 2011). However, despite this capability to express varying versions of the self, research has exclusively focused on a change of self-concept, or identity shift, as a result of internalizing the intentional presentation of one singular consistent trait (Carr \& Foreman, 2016; Gonzales \& Hancock, 2008; Walther et al., 2011). To further identity shift research, the present study sought to explore this phenomenon of multiple, oppositional self- 
presentations within a single channel and the effects these presentations have on one's selfconcept. 


\section{CHAPTER II: REVIEW OF LITERATURE}

\section{Identity Shift}

Identity shift refers to the alteration of one's self-concept through the selective selfpresentation of a given trait (Gonzales \& Hancock, 2008). Identity shift is built upon the hyperpersonal model of communication (Walther, 1996; Walther et al., 2011), which posits that as a sender encodes a message for a recipient, they are likely to portray themselves in a manner perceived to be desirable to their communicative partner, so as to encourage positive, continued conversation (Walther, 1996). The sender's message is then sent through a disentrained channel to their desired recipient. Upon receiving the message, the recipient begins to build an idealized concept of their conversational partner based on the characteristics of the selective selfpresentation provided in the message, providing feedback to the sender reinforcing the sender's presentation. Identity shift research suggests that as a person self-presents through a mediated channel, their selective self-presentations can lead to a change in their self-conception (Gonzales \& Hancock, 2008).

As a message sender receives the feedback to their previous self-presentation, it is internalized as a(n) [in]validation of their self-presentation (Gonzales \& Hancock, 2008; Walther, 1996). Depending on how a message receiver felt the sender's self-presentation did (not) align with the receiver's expectation of the sender's self-presentation, the receiver will respond to the sender with feedback that expresses (dis)approval towards the sender's presentation (Walther, 1996). This feedback is a message sender's primary means of creating a more appealing self-presentation for their message recipient in their subsequent iteration of the communication cycle, so they internalize their partner's feedback as a means of understanding who they, the sender, are to the receiver, to ensure they maintain a stable and receiver-approved 
self-presentation. Over time, this process repeats, with each iteration producing a furtheridealized concept of a message sender for both the receiver and the sender. For the sender, this deliberate selective self-presentation can foster identity shift (Walther, 2011).

Identity shift was first explored through analysis of the effects of public and private selfpresentations of introversion/extraversion on one's self-concept (Gonzales \& Hancock, 2008). Gonzales and Hancock found participants internalized their assigned trait presentation, introversion or extroversion, when the trait was presented publicly; thus Gonzales and Hancock posited the act of public self-presentation was the primary instigator of an identity shift effect. Later research (e.g., Walther et al., 2011), drawing on the hyperpersonal model's feedback intensification loop, demonstrated that identity shift was enhanced by feedback, and even the anticipation thereof (Walther, 1996). Expanding on the role of feedback on identity shift within a hyperpersonal context, Carr and Foreman (2016) noted that identity shift effects can be intensified through reception of public (over private) feedback, particularly from relationally close partners. By furthering identity shift research within the hyperpersonal model, researchers noted that identity shift can be a cyclical process of selective self-presentations influenced by disentrained, or mediated and asynchronous, feedback, rather than as a side effect of public commitment to a self-presentation (Carr \& Foreman, 2016; Walther, et al., 2011).

As this brief summary illustrates, identity shift research to date has primarily focused on feedback and its effects (Carr \& Foreman, 2016; Carr \& Hayes, 2019; Gonzales \& Hancock, 2008). The present study sought to return to Gonzales and Hancock's focus on the act of selfpresentation, aided and informed by the benefit of more recent studies' grounding of the theory within the hyperpersonal model (e.g., Carr \& Foreman, 2016; Walther, et al., 2011). In doing so, 
the present study provides greater understanding of how one is affected by differing selfpresentations.

\section{Mediated Self-Presentation}

\section{Self-Presentation}

Interaction demands presentation. Communication begins with the encoding of a message, to be sent across a given medium, to then be decoded by message receiver(s) (Schramm, 1960). Innate to the process of message encoding is the message sender's word choice, medium choice, and personal influences and decisions on/about their message. Each aspect of a message is deliberately chosen during message encoding, and therefore uniquely links every communicator's message back to themselves as a unique communicator (Schramm, 1960; Walther, 1996). This individuality of communicative choice is not only reflected in the media through which one communicates, but also through the selective presentation of the self that one communicates.

Providing a framework for how one comes to self-present, Goffman's (1959) theory of dramaturgy poses that every person has a front and back stage. The front stage serves as the front, or face, that one performs to any given, contextually dependent audience. The back stage is composed of all the unfiltered, behind the scenes thoughts and emotions that a person possesses, which are drawn from as needed to assemble a front stage. When entering into a communicative interaction, a front stage is built, shifting to foreground whatever aspects of self are most appropriate for the audience to whom one performs. As a result of these selective selfpresentational choices, one's audience comes to know the speaker as the front stage they present to their audience, and in turn, the speaker comes to know themselves through observing the front stage that they curate and through judging reactions to their performance (see Bem, 1972). This 
process of selective self-presentation of facets of one's self is capable of producing identity shifting effects when conducted specifically through mediated, disentrained channels, a category notably inclusive of computer-mediated channels (Gonzales \& Hancock, 2008; Walther, 1996; Walther et al., 2011).

The primary advantage computer-mediated communication, and mediated channels more broadly, offers over face-to-face communication is the ability to be in greater control of one's self-presentation, and to carefully curate the exact performance that one wishes as a result of disentrainment (Walther, 1996). Unlike in face-to-face communication, to which dramaturgy was initially applied, mediated communication can be asynchronous (Goffman, 1959; Walther, 1996). Asynchronous, disentrained channels convey information in fragments, rather than as a complete, live performance as occurs in person (Walther, 1996). Thus, there is no inherent need for a front stage to be created in its entirety at the start of a conversation, and as a result the boundaries of the front stage are able to be explored and mapped throughout the conversation (Goffman, 1959; Walther, 1996).

\section{Mediation}

Walther (1996) explains the ability to selectively self-present through mediated channels as a product of channel disentrainment.

\section{Disentrainment}

Channel disentrainment lacks a formal definition but is generally characterized by the capability for communicators to engage in selective self-presentation strategies, often via asynchronicity between communicators. Walther (1996), explaining disentrained channels in relation to the hyperpersonal model of communication, provides the distinction that whereas entrained channels require participants to sacrifice a certain amount of their time to a 
communicative interaction as it happens, disentrained channels allow participants to come and go from a conversation as they please. For example, a face-to-face conversation requires active participation and attention from all involved parties until the conversation ends, whereas a conversation through a disentrained channel, such as sending direct messages through Instagram, does not.

In a disentrained channel, communicators can sporadically engage with an ongoing conversation as is convenient for them, without a need for being simultaneously available for all communication. However, disentrainment is not a binary concept, as various media provide varying degrees of asynchronicity, and thus disentrainment. Writing a letter is inherently more disentrained than sending a Snapchat video. Snapchat can simulate synchronicity quite easily, as response times are only limited by Internet speed and desire to respond on the part of each participant, whereas when sending a letter, response times are dictated by speed of mail delivery, which slows conversation tremendously. A more nuanced conceptualization of disentrainment would be to view channels as possessing various degrees of disentrainment, with face-to-face communication being the baseline for a completely entrained channel and a message in a bottle as a baseline for complete disentrainment. As channels provide greater and greater affordances for selective self-presentation, and greater asynchronicity, they in turn are understood as being more disentrained.

\section{Deliberate Self-Presentation}

This resultant ability to take one's time in continuing a disentrained conversation helps users adapt to the lack of face-to-face cues (e.g., non-verbal cues) available to them as a result of their chosen channel's disentrainment (Walther, 1996). Disentrainment affords communicators a greater allocation of cognitive resources to use in crafting their self-presentations, allowing them 
to more carefully and considerately select which aspects of themselves they wish to highlight.

This lack of available cues also gives communicators the greater opportunity to curate their selfpresentation, or front stage self, towards their communicative partner's interests, as many identifying traits are not immediately revealed to communication partners as they would be faceto-face due to channel disentrainment (Goffman, 1959; Walther, 1996). For example, should someone create a new Twitter account, they find themselves without any prior tweets, profile images, or data to tie them back to any previous self-presentations on the platform. This new Twitter user can then construct their account and presence entirely based on what they choose to self-present, and therefore the front stage they decide to build (Goffman, 1959). Additionally, the benefits of disentrainment lead conversational participants to experience greater relational satisfaction as their selective self-presentations are validated (Schlenker \& Trudeau, 1990). Thus, channel disentrainment reinforces the desire to selectively self-present (Walther, 1996).

\section{Multiple Front Stage Selves}

Channel disentrainment also affords the creation and managing of multiple selective selfpresentations (Hogan, 2010). Unlike face-to-face communication, disentrained channels afford communicators the ability to hold conversation with several exclusive audiences at once (e.g., family members, roommates, coworkers, etc. in the same channel) (Walther, 1996). Within each separate communicative event, self-presentations may vary as communicators adapt their front stage presentations to best suit the audience to whom they are speaking (Goffman, 1959). Therefore, a communicator may simultaneously present entirely different selves, to different groups, at the same time. Identity shift research suggests that selective self-presentation leads to a change in a communicator's self-perception, but no research has yet to explore identity shift 
effects of maintaining multiple, non-similar self-presentations, as is entirely possible through channel disentrainment.

\section{Strategic Online Self-Presentation}

Self-presentational consonance refers to the degree to which an individual is successful in creating a self-presentation that aligns with the self they believe their audience expects. Creating a consonant self-presentation for a pre-existing or co-located group, such as one's coworkers or one's extended family is challenging, but achievable (Litt, 2012). While these groups contain numerous individuals, each with different expectations for one's selfpresentation, these groups' expectations are often more similar to one another than they are different due to shared context. An individual's self-presentation at work is likely to be consistent across all work interactions due to the larger expectation of professional etiquette. While an individual may self-present in slightly different ways based on the exact person to whom they are speaking, their self-presentations will likely remain similar across each interpersonal interaction. Therefore, creating a consonant self-presentation for work colleagues does not require accountability for a great degree of self-presentational variance, making consonant self-presentations easier to achieve.

In contrast, self-presentational strategies must change when communicating simultaneously with different audiences, particularly when these otherwise separated audiences are drawn together through computer mediated channels, such as social media (Hogan, 2010; Marwick \& boyd, 2011), and consonance may be harder to achieve. Social media afford someone the capability to simultaneously broadcast a singular message containing a singular self-presentation to a multitude of groups, each of which may have a different pre-existing perception of a singular communicator. Unlike with face-to-face entrained communication, 
maintaining a consonant self-presentation on social media is extremely difficult due to massive audience sizes found on most people's social media accounts (Litt, 2012). For example, in 2014, Facebook users reported having an average of 338 people on their friends list (Smith, 2014).

\section{Context Collapse}

Due to the large number of people who become conjoined into one audience of social media 'friends', social media users/communicators can experience context collapse, or the distillation of several disparate audiences to whom one may speak in any given face-to-face context coalescing into a singular audience (boyd, 2008; Litt, 2012; Marwick \& boyd, 2011). Self-presentational consonance is of particular importance in situations of context collapse (boyd, 2008). Various social circles may hold various conceptions of a singular person, and their social media account must now seek to balance multiple competing expected self-presentations at once (Litt, 2012). For example, what one may post directed at one's college friends may be drastically different from what one posts directed at one's extended family; strong liberal political opinions may play well to an audience of your peers, but not to older, more conservative folks. Needing to construct a consonant self-presentation for several otherwise-disparate audiences creates tension surrounding constructing a front stage, as now one's performance must appeal to a much larger and diverse group of people, some of whom may hold entirely different expectations of an individual (Goffman, 1959). Litt (2012) coined the term imagined audience to refer to this amorphous audience of a given social media posts' potential viewers. While systems' privacy settings can be used to manage this broadened audience, these tools require active, conscious engagement to be effective (Duguay, 2016). As a result, social media users frequently are forced to consider their entire imagined audience en masse when presenting themselves (Hogan, 2010; Litt, 2012). 


\section{LCD Audience Member}

However, considering hundreds of people, and one's perception of each of their expectations of one's self, at once is too great a task to take on. Instead, a social media user can identify their lowest common denominator (LCD) audience member, or the audience member whose expectations for one's self-presentation are most fragile (Hogan, 2010). From this LCD audience expectation, individuals then tailor their self-presentations towards said member(s). That is to say, as one readies a social media post, one must imagine who is most likely to negatively receive one's proposed self-presentation, whether that be one's boss, one's grandmother, or someone one has never met before, but may still have access to one's post and pose a threat to one's livelihood (e.g., one's pastor may end up seeing a scantily clad photo on one's Instagram). Then, one must carefully consider how one will, or will not, achieve selfpresentational consonance for their LCD audience member, and therefore the greatest degree of consonance for their audience en masse. Past research found that the greater degree to which an audience is unknowable to a communicator, the more the communicator will rely on the LCD of their imagined audience to maximize the expected likelihood their given self-presentation is positively received. (Gil-Lopez et al., 2018). Therefore, an LCD approach to social media selfpresentations appears to function as a coping mechanism for stressors of presenting multiple facets of one's self created by context collapse.

Creating an LCD-consonant self-presentation on social media is much easier proposed than completed, however. While traditionally one may consider the act of self-presentation as being a pseudo-performance for an audience, Hogan (2010) instead argues that self-presentations through disentrained channels such as social media are instead more similar to art pieces at an exhibition. The audience that may view one's social media posts is in some ways unknowable, as 
followers and friends are only those with first access. Each social media site's algorithm acts as a museum curator, bringing out posts from the warehouse for display as they see fit, depending on their programming goals. Thus, self-presentations within a disentrained social medium are not directed at any one person, but "submitted" to one's broad/general audience (Hogan, 2010, p. 377). Locating and self-presenting towards one's LCD audience member, then, is not an act of audience management, but rather is an exercise in discovering the most stable, consonant, milquetoast self-presentation possible for a communicative event that has no beginning nor end in order to avoid the negative impacts of context collapse (Hogan, 2010; Marwick \& boyd, 2008).

An LCD approach to self-presentation does not solve the problem of context collapse - it only holds it at bay. Maintaining a fully LCD-consonant self-presentation is a nearimprobability, despite best efforts by social media users (boyd, 2008; Hogan, 2010; Litt, 2012). Even if one can maintain a fully consonant self-presentation with their audience's expectations, their post can still be shown to someone that they did not expect, through a social media site's algorithmic curation, and that person can take offense at one's self-presentation (Hogan, 2010). Acknowledging the difficulty in achieving constant LCD-consonant self-presentation across all audiences on social media leads to the assumption, then, that at some point a social media user will present themselves in a way that creates dissonance with a subsect of their collective audience's expectations. In response to any given event, different sects of one individual's social media audience may expect entirely different self-presentations and an individual may only be able to self-present in one manner. Rooting the inevitability of audience expectation violation in the hyperpersonal model and identity shift research, there is likely to be some net effect on a 
social media user's self-perception after dissonant self-presentation (Walther, et al., 2011). To explore the effects of presenting an intentionally dissonant selves, this study asked:

RQ: What (if any) identity shift occurs when you self-present diametrically opposed traits? Cognitive Dissonance

Striving for self-presentational consonance is likely to cause an individual a certain degree of cognitive dissonance (Carr, 2019). Cognitive dissonance refers to cognitive tension produced when an individual is made aware of disparity between their personal values and the actions they are taking or have taken (Festinger, 1953). Previous identity shift research has addressed the potential for cognitive dissonance reduction strategies to interact with the identity shift process, as the act of trying to manage a new self-presentation and undergo the effects of the hyperpersonal feedback process can cause mental stress, and therefore potential cognitive dissonance (Carr, 2019).

\section{Boomerang Effect}

Cognitive dissonance resulting from a non-LCD-consonant self-presentation may be resolved by reinforcing one's initial presentation/stance on a topic, rather than by one changing one's attitudes to match their behavior. Hovland et al. (1953) referred to this technique as a boomerang effect. For example, if someone who believes themselves to be a safe driver accidentally runs a red light, rather than internalizing that they may not be as safe of a driver as they had thought, they will subsequently drive with extreme caution to ease their cognitive dissonance and assure themselves that they are, in fact, a safe driver.

In the context of the present study, a boomerang effect could manifest as an identity shift seeking to reaffirm one's consonant self-presentation in the face of dissonant behavior. The hyperpersonal model is built upon constructing and continuously reaffirming a specific self- 
presentation upon reception of feedback from a conversational partner in order to maintain a consistent self-presentation with your audience's expectations (Walther, 1996). It is in the best interest of a communicator to maintain a stable self-presentation, to please their conversational partner and invite further communication. Within the context of social media, this desire is codified as the LCD approach (Hogan, 2010). Therefore, in the interest of continuing successful communication, a message sender is likely to quickly distance themselves from a dissonant selfpresentation by shifting their self-presentation back towards their audience's expected selfpresentation(s) to ensure self-presentational consonance in subsequent interactions or assessments (Carr, 2019; Walther, 1996). This response to self-presentational dissonance was hypothesized to have occurred in previous identity shift research (Carr, 2019).

Carr (2019) performed an identity shift study seeking to shift participants' selfperceptions along an altruism-selfishness spectrum. The study produced null results, noting that a boomerang effect could have occurred for the study participants within the selfish condition, as participants' study-prompted selfish behavior clashed with their Midwestern cultural value of altruism. In response, participants may have shifted their self-concept further in the direction of altruistic action to resolve their potential cognitive dissonance (Carr, 2019; Hovland et al., 1953). After self-presenting as greedy, participants' cognitive dissonance may have arisen specifically from not self-presenting in-line with what an LCD audience member, a potential fellow Midwesterner, would expect of them. Thus, when given the opportunity within the study to act either greedily or altruistically, rather than act in accordance with study manipulation, participants course-corrected their behavior towards altruism as a means of shifting their selfpresentation to a more consonant state (Carr, 2019). By following a dissonant self-presentation 
with a consonant self-presentation, participants may have been able to resolve their cognitive dissonance.

Implicit to this argument is the operationalization of cognitive dissonance reduction as a response to identity shift. As noted, participants believed themselves to be altruistic, which would suggest that those with whom they communicate would view them as altruistic as well. However, study conditions required they self-present to their audience as being selfish. In anticipation of their audience's reaction to the dissonant self-presentation, participants had to cognitively work through their discrepant behavior to provide themselves an explanation for their behavior. To accomplish this internalization of discrepant behavior, participants' self-concepts may have followed the pattern of a boomerang effect as a means of eliminating the cognitive dissonance caused by their LCD-dissonant presentation, shifting away from the dissonant selfpresented trait. By returning to a consonant self-presentation, participants may have felt they would be able to assure themselves this discrepancy was not an indication of a new trend, but an outlier in the larger, cohesive self-presentation that has been given off to this point. Therefore, an LCD approach to self-presentation does not eliminate the stressors of context collapse, but instead may act as a barrier between the user and these impacts (Hogan, 2010; Marwick \& boyd, 2008). Because Carr's (2019) study conditions took away participants' abilities to self-present in-line with what they believe their LCD audience member would expect of them in the manipulation portion of the experiment, participants were forced to internalize the effects of context collapse and turned to identity shift as a solution. While this process was only post-hoc suggested in Carr's study, the present study will formally test the hypothesis of an identity shift boomerang effect. Thus, as initial response to RQ1, the present study proposed: 


\section{H1: An individual self-presenting a trait that differs from their extant self-presentation experiences identity shift in the direction of their extant self-presentation.}

\section{Process Rationalization}

Though previous work suggests individuals may shift away from a non-consonant self, there is also a theoretical potential for them to shift toward the non-consonant trait. Previous cognitive dissonance research has examined self-concept change in the direction of dissonant behavior as a successful strategy of cognitive dissonance reduction, rooted in self-perception theory (Bem, 1972; Elliot \& Divine, 1994). Elliot and Divine (1994) explored dissonant selfpresentation and resultant rationalization strategies through instructing participants to write an essay that was incongruent with their prior beliefs about a tuition increase at their university. The experience “...generated psychological discomfort, which gradually diminished (of its own accord) over the course of the essay-writing period" (Elliot \& Divine, 1994, p 388). In interpreting their results, Elliot and Divine (1994) hypothesized a potential explanation for the phenomenon, suggesting, "Attitude change in this scenario would not be driven by psychological discomfort, but would simply be a function of cognitive, self-perceptual processes..." (p 388). This proposes that participants were experiencing diminished cognitive dissonance regarding writing a counter-attitudinal essay due to changing their position entirely as a result of seeing themselves construct an argument against their previous stance, as identity shift research would suggest (Elliot \& Divine, 1994; Gonzales \& Hancock, 2008).

A secondary experiment to test their hypothesis of attitude change as a cognitive dissonance reducer found non-significant results (Elliot \& Divine, 1994). However, lack of support for the hypotheses in the second study may be an artifact of study design, not of the phenomenon itself. While the researchers distributed a consent form emphasizing personal 
responsibility for the messages that their participants were composing (messages both consonant and dissonant with their previously held attitudes), the researchers did not prompt their participants to acknowledge their messages as being authentically produced by themselves through ensuring deliberate personal identification within their essays. As seen in previous identity shift research, an identity shift will only occur should the subject internalize identification with being the producer of a given message (Carr \& Hayes, 2019, Study 1). Furthermore, public commitment research (Tice, 1992) finds that a self-concept adjustment is most prominent when a demonstrated trait is tied to an existing, personal memory, linking to Carr and Hayes' (2019) assertion that identification must be clear in order for identity shift to occur. As a part of this, the participant's free will to choose to participate in their trait demonstration must be made salient in order to produce attitude changing effects (see also Tice, 1992). For identity shift effects to influence self-presentation, an individual must feel they are authentically presenting themselves to an audience, rather than demonstrating a trait because they were prompted by a researcher (Carr \& Hayes, 2019).

Additional cognitive dissonance research has found the effects of cognitive dissonance are reduced when an attitude change occurs in the direction of the participant's 'new' attitude (Harmon-Jones, 2000). Thus, changing one's self-concept and self-presentation serves as a viable cognitive dissonance reduction strategy, suggesting that identity shift towards a nonconsonant self-presentation may also be a successful strategy for managing non-consonant selfpresentations (Cancino-Montecinos et al., 2018; Harmon-Jones, 2000). Additionally, engaging an identity shift towards the dissonant behavior would also resolve dissonance resulting from context collapse issues suffered from an unavailability of an LCD self-presentation. By embracing the LCD-dissonant behavior, an individual would effectively reconstruct their LCD 
self-presentation to include the previously dissonant behavior. This eliminates the tension produced by context collapse surrounding the dissonant behavior, and thus eliminates cognitive dissonance through relieving the original tension.

Furthering this link to the hyperpersonal model and identity shift, researchers have found that the greatest degree of participant self-concept adjustment occurs after an in-person interaction, with the expectation that there will be another face-to-face interaction with the participants' conversational partner at a later date (Schlenker et al., 1994; Tice, 1992). The induced belief of accountability one has to their self-presentation, again, mirrors the hyperpersonal expectation for future interaction and the desire to selectively self-present that this expectation prompts (Walther, 1996). Therefore, it is entirely possible Elliot and Divine's (1994) hypothesis was correct, but they lacked the necessary methodological practices to obtain significant findings. Previous identity shift research similarly produced null results due to lack of clear identification between the participant and the message they produced (Carr \& Hayes, 2019, Study 1; French \& Hancock, 2016). However, unlike Elliot and Divine (1994), Carr and Hayes (2019) were able to locate this issue within the hyperpersonal framework of identity shift. Carr and Hayes targeted increasing participants' identification with their self-presentations, and with the simple inclusion of asking for participants to identify themselves by providing their names and hometowns, the researchers were able to produce significant results with an otherwise identical methodology to their previous iteration of their study (Carr \& Hayes, 2019, Study 2). For these reasons, the present study hypothesized when self-presenting a non-consonant self, a participant will shift their self-concept to align their identity with their non-consonant presentation, thereby reducing their cognitive dissonance (Harmon-Jones, 2000). 


\section{H2: An individual self-presenting a trait that differs from their extant self-presentation experiences identity shift in the direction of their non-normative self-presentation.}

\section{Audience Expectations}

$\mathrm{H} 1$ and $\mathrm{H} 2$ represent counterhypotheses, anticipating separate outcomes from the same communicative acts. Between the two, a boomerang effect $(\mathrm{H} 1)$ is expected to demonstrate greater identity shift than process rationalization $(\mathrm{H} 2)$. While attitude change is a successful way to reduce cognitive dissonance (Elliot \& Devine, 1994; Harmon-Jones, 2000), when presented with a salient option of changing their behavior and attitudes, individuals are unlikely to change their attitudes to reduce their cognitive dissonance (Poe Dossett \& Hayes, 2009; Wombacher, et al., 2019). Additionally, the perceived accessibility of an attitude change, or the efficacy a participant feels towards changing their attitude, is related to the malleability of the attitude in question, and if the individual determines their behavior to be within or outside of their predicted range of acceptance for said behavior (Schlenker \& Trudeau, 1990; Vraga, 2011). Malleability of self-belief, or the range of behavior in which one feels comfortable self-presenting given trait, is determined through how critically valuable any given trait is to an individual's self-presentation, as, "Strong self-beliefs are most influenced by slightly discrepant behaviors that fall within the individual's latitude of acceptance, and weak self-beliefs are most influenced by more discrepant behaviors" (Schlenker \& Trudeau, 1990, p. 30). As a result, the degree of cognitive dissonance experienced and the resulting perception of attitude change efficacy may vary depending on how strongly held their self-beliefs are about their previous self-presentations of said behavior. As an individual's LCD audience member can be understood as reflective of an individual's most widely acceptable and consonant self-presentation (Hogan, 2010), then a self-presentation in line with one's LCD audience member's expectations would be similarly reflective of one's core 
values and attributes. Thus, the present study hypothesized that due to previous evidence of an identity shift boomerang effect in the face of a non-consonant self-presentation (Carr, 2019), an individual presenting multiple, diametrically opposed self-presentations will see an identity shift towards the self-presentation most consonant with their LCD audience member's expectations of them.

\section{H3: Identity shift is greater toward an LCD-consonant self-presentation than an LCD- dissonant self-presentation.}

\section{Strength of Self-Belief}

How strongly an individual identifies with a trait prior to an identity shift may moderate the effect of said identity shift. Public commitment research suggests that, as a general rule, "once people claim to 'be' a particular type of person they have obligated themselves to behave consistently with that identity...", echoing the concept of self-presentational consonance discussed above (Schlenker et al., 1994, p. 21). This obligation is not necessarily firm, however. Rather, research (Schlenker \& Trudeau, 1990) demonstrates that an individual's self-concept exists in two forms: a fixed, unchanging bundle of firm beliefs and notions about one's self, and a more amorphous, shifting spectrum of less tightly held beliefs that are malleable. Behaviors and self-beliefs in the latter category are not viewed as fixed, but as existing along a spectrum of acceptable expressions of said behaviors. Due to this range of acceptability, in any given circumstance an individual has access to a range of acceptable behavior of a given trait, which allows for self-presentational discrepancy. In other words, while people do hold some behaviors as integral to their personhood and self-presentation, they also accept that they may be contradictory at times about cursory behaviors, and sway between inconsistent opinions, beliefs, and actions. 
In a study analyzing the impact of self-presentation on self-concept, when asked to demonstrate behaviors that differed from their norms, participants were found to internalize behavior discrepant with their prior self-beliefs as long as that behavior fell within their selfprescribed range of acceptable demonstration for that behavior (Schlenker \& Trudeau, 1990). Additionally, participants with weak self-beliefs regarding a given behavior were found to internalize all exhibitions of said behavior, regardless of its location within any range of acceptability. Participants with tightly held self-beliefs were only able to internalize behaviors within their self-prescribed range of acceptability for said behavior and dismissed their demonstrations of highly discrepant behaviors. These findings mirror the predicted results of identity shift, as participants found themselves shifting their self-concept to more closely resemble their self-presentational behavior (Gonzales \& Hancock, 2008; Schlenker \& Trudeau, 1990). Thus, strength of self-belief about a given self-presentation or trait demonstration can be seen to affect how external behavior affects evaluation of one's self-concept. For this reason, the present study hypothesized:

H4: Strength of held self-belief moderates the effects of self-presentation on identity shift. 


\section{CHAPTER III: METHODS}

\section{Participants}

Participants were recruited through convenience sampling of a mid-size midwestern university via a departmental research board (see Appendix A). A total of 54 participants successfully completed the survey. Participants self-reported their age $(M=22.04, S D=2.46)$, and were primarily female in sex $(n=42,77.78 \%)$, with one participant who declined to respond. Participants were primarily female in gender $(n=43,79.63 \%)$. The majority of participants were undergraduate students $(n=39,72.22 \%)$, however there were also several graduate student participants $(n=14,25 \%)$, and one continuing education student. Demographic information collected was generally reflective of the university's student body (see Illinois State University, 2019).

\section{Self-Presented Trait}

This study asked participants to self-present as being both conscientious and unconscientious as defined within the Big Five character trait framework (John \& Srivastava, 1999). The Big Five is a character trait taxonomy used in psychology research that identifies five primary human character traits: extraversion, neuroticism, openness to new experiences, agreeableness, and conscientiousness. While any Big Five personality trait could be implemented in this study, conscientiousness was chosen for several reasons. First, introversion/extraversion has been employed in several previous identity shift studies (e.g., Carr \& Foreman, 2016; Gonzales \& Hancock, 2008; Walther, et al., 2011); this study intentionally sought to explore identity shift along a yet-untested construct. Second, in light of the politicization of socializing due to the COVID-19 pandemic, and the association between socialization and perceived extraversion, this study sought to avoid potential participant misattribution of value to 
introversion/extraversion, as such value attribution may affect participant responses.

Conscientiousness was defined for participants such that a highly conscientious individual is someone who has strong self-discipline, is very organized, goal-oriented, and careful in making decisions (John \& Srivastava, 1999). Alternatively, unconscientiousness was defined such that an unconscientious individual is someone who has weak self-discipline, is disorganized, not goaloriented, and impulsive in making decisions (John \& Srivastava, 1999). In this way, conscientiousness was the personality trait used in this study to be presented and potentially shifted.

\section{Procedures}

An experiment was conducted via an online survey platform, Qualtrics, to test hypotheses and answer the research question. After providing consent to participate (see Appendix C), participants were prompted to recall their social media audience on Facebook and manually identify six separate groups that exist within their audience on Facebook. Examples groups provided to participants included "Facebook friends from your chess club, such as John, Tim, and Eric," and "Facebook friends from your statistics class, such as Vivian, Hannah, and Celia." This task was included to ensure that participants had a clear and fixed concept of the audiences to whom they would be self-presenting during the study. Facebook serves as a strong referent point for ensuring the participant imagines an audience that would cause the participant to experience context collapse due to the large number of Facebook friends the average person has (Smith, 2014).

After identifying various social groups that may see their self-presentation, participants then completed pre-test self-rating and other-rating conscientiousness scales (Ashton \& Lee, 2009), and a strength of self-belief scale (Schlenker \& Trudeau, 1990). Before advancing to the 
experimental portion of the survey, participants played Tetris for five minutes as a distractor task. Tetris has been used in previous research to ensure that there are no carryover order effects from any potential priming that occurred within the pre-test (Bowman et al., 2013; Gray et al., 2014), and does not influence participants in any meaningful way, while still keeping them engaged in the study at hand (Huff et al., 2016; Page \& Coxon, 2017; Tian \& Häubl, 2016). After completing the non-research task, participants were prompted to complete a simulated sign-up to Facebook, by reporting their first and last name, hometown, and uploading a profile photo, following an adapted form of previous identity shift research protocol (e.g., Carr \& Hayes, 2019).

Next, participants were instructed to recall two specific real-life events. One prompt asked participants to recall an instance in which they behaved conscientiously, using the prompt, "We would like you to recall a real-life event in which you demonstrated strong self-discipline, and/or were very organized, goal-oriented, and careful in making decisions. Do not lie, but base your response on personal experiences that would exemplify someone who acts in this manner. In the text box below, in 3-5 sentences, please write a Facebook post about the event in question, highlighting how you demonstrated these traits with your actions." In the other prompt, participants were asked to recall a time they in which they behaved unconscientiously via the prompt, "We would like you to recall a real-life event in which you demonstrated weak selfdiscipline, and/or were disorganized, not goal-orientated, and impulsive in making decisions...". Qualtrics randomized the order of trait presentation, so that participants either self-presented as conscientious or unconscientious first, to avoid confounding order effects. Additionally, participants were explicitly directed not to lie, but draw from their previous experiences in responding to prompts. Emphasizing that participants be truthful in their self-presentation is 
integral to identity shift (Carr \& Hayes, 2019; Carr et al., in press), as drawing on falsehoods may not produce the desired identity shift effects (Carr et al., in press; Gonzales \& Hancock, 2008).

Following the self-presentational portion of the study, post-test measures self- and otherratings of conscientiousness were collected, using the same scales as were implemented previously in the survey. Lastly, demographic information was collected from every participant. Once finished with the survey, participants were thanked for their time and then automatically redirected to a separate survey that collected identifying information to be sent to participants' instructors to provide course [extra] credit commensurate with the course policies.

\section{Measures}

Several established and previously-validated standard measures were used to operationalize key variables in this study (see Appendix B). Previous identity shift studies (see Peña \& Hill, 2020) demonstrate that identity shift effects often manifest in very slight changes in self-reported trait measurements. Where appropriate, 11-point scales were therefore adopted to capture greater nuance in the measurement of study variables.

\section{Conscientiousness}

Ten items relating to conscientiousness were drawn from the HEXACO-60 personality assessment (Ashton \& Lee, 2009) to operationalize conscientiousness in the present study. The items were adapted from 5-point Likert-type scales to 11-point Likert-type scales to increase capacity for data variability. After recoding reverse coded items, higher scale means corresponded to higher degrees of conscientiousness. The scale demonstrated good reliability across four implementations, as reliability scores ranged from $\alpha=.77-.83$. 


\section{Self-Belief Strength}

Strength of self-belief was measured through Schlenker and Trudeau's (1984) latitude of acceptance scale. The three-item scale prompted participants to first identify the point on the 11point scale that best represents their association of themselves with conscientiousness, then identify the lowest and highest points on the scale, respectively, that could represent their degree of conscientiousness.

\section{Additional Measurements}

At the end of the survey, participants were asked to indicate the degree to which they desired to be more or less conscientious than they had previously self-reported (Hudson \& Roberts, 2014) on an 11-point Likert-type scale for a single item. Finally, demographic information was collected regarding age and gender identity, following protocol articulated by Reisner et al. (2015). 


\section{CHAPTER IV: RESULTS}

\section{Hypotheses 1 \& 2}

Hypotheses 1 proposed participants experience an identity shift boomerang effect, shifting their self-concept further strengthen their extant self-presentation, whereas Hypothesis 2 proposed the identity shift effect would occur in the opposite direction of a participant's extant self-presentation. To test these competing hypotheses, participants were divided into two categories, high- and low-conscientiousness, using a median split based on averaged pre-test self-ratings of conscientiousness (Median $=8.00$, Range $=4.60-10.20)$. The median split served to distinguish between participants who identified as more or less conscientious pre-test, respectively, to ascertain what relationship each group's identity shift had in post-test measurements to their initial pre-test degree of conscientiousness. A median split was employed as opposed to trisecting participants due to low participant sample size and resulting desire to keep as many participants in each group as was possible to avoid differences in answer-toanswer responses overinfluencing results. Furthermore, while the range of responses was limited, a median split as opposed to a mean split was chosen in order to better balance participant numbers across the high- and low-conscientious groups in response to participants generally rating themselves as higher on the conscientiousness scale, which would have weighted group distribution in favor of the high-conscientiousness group. Two one-sample $t$-tests were performed to analyze between-group differences in change in conscientiousness measured prior to and following their selective self-presentations. A one-sample $t$-test was implemented, rather than a two-sample t-test, as groups were compared against their net change in self-rated conscientiousness between pre- and post-test measurement. Individuals in the highconscientiousness group $(M=-0.27, S D=0.80$. $)$ did not experience an identity shift towards 
either their more or less conscientious self-presentation, $t(25)=-0.27, p=.09, d=-0.70$.

Individuals in the low-conscientiousness group $(M=0.31, S D=0.61)$ experienced an identity shift towards their more conscientious self-presentation, $t(27)=2.73, p=.011, d=1.05$. Thus, Hypothesis 2 was partially supported for low conscientious individuals, and Hypothesis 1 was not supported.

\section{Hypothesis 3}

Hypothesis 3 proposed participants' identity shifts would be stronger towards a presentation consonant with their LCD audience member's expectations. To test this hypothesis, participants were divided into high-expectancy and low-expectancy groups via a median split based on averaged pre-test other-ratings of conscientiousness $($ Median $=7.85$, Range $=4.30$ 11.00). The median split served to distinguish between participants who believed their audience saw them as more or less conscientious, respectively, in order to determine directionality for subsequent identity shift effects. Two one-sample t-tests were performed to determine betweengroup differences in change in conscientiousness pre- and post-test. Individuals who reported more-conscientious audience expectations $(M=0.12, S D=0.79)$ did not shift towards being either more or less conscientious $t(26)=0.80, p=.43, d=0.31$. Individuals who reported lessconscientious audience expectations $(M=-0.06, S D=0.73)$ did not shift towards being either more or less conscientious $t(26)=-0.42, p=.68, d=-0.16$. Thus, Hypothesis 3 was not supported.

\section{Hypothesis 4}

Hypothesis 4 proposed that strength of held self-belief would moderate self-presentation effects on identity shift. Regressing the effect of self-presentation on change in conscientiousness, with a moderating term for strength of self-belief, revealed a significant 
model, $F(3,53)=4.88, p=.005, R^{2}=.23$. However, although the direct effect of selfpresentation on identity shift was significant, $\mathrm{b}=-.66, p=.01$, reflective of the partial-support of $\mathrm{H} 2$, the strength of self-belief did not moderate that effect, $\mathrm{b}=-.34, p=.41$. Thus, Hypothesis 4 was not supported. 


\section{CHAPTER V: DISCUSSION}

The present study advanced identity shift research through exploring effects of consecutive, diametrically opposed self-presentations on identity shift effects. Results demonstrated several boundaries and extensions of identity shift. Primarily, results indicate that identity shift can occur in situations in which one individual makes multiple, contrasting selfpresentations, extending identity shift research into more complicated self-presentation scenarios.

\section{Theoretical Implications}

Hypothesis 1 and Hypothesis 2 proposed oppositional conclusions as to how presenting as both conscientious and non-conscientious would affect participants. H1 was founded upon results from previous identity shift literature (Carr, 2019) suggesting that in the face of a selfpresentation incongruent with previous self-presentations, an individual is likely to experience an identity shift boomerang effect, shifting their self-concept to be more like their extant selfpresentations. H2 drew from past public commitment research (e.g. Elliot \& Devine, 1994) to propose that individuals would experience an identity shift towards the self-presentation that was less congruent with their previous self-presentations as a means of reducing cognitive dissonance produced via non-normative self-presentation. H2's partial support, with less-conscientious individuals experiencing an identity shift towards being more conscientious, expands the boundaries of identity shift. The present study's results support the argument that multiple competing, oppositional self-presentations can result in a net identity shift effect on an individual. Identity shift research has previously only demonstrated an identity shift effect in situations where participants were prompted to execute a singular, mono-directional selfpresentation. While one could have inferred that cumulative effects of multiple self-presentations 
would result in an identity shift, the effect had not yet to this point been demonstrated. Knowing that an individual can self-present in diametrically opposed manners and still experience an identity shift opens the door to identity shift research surrounding net effects of cumulative, diverse self-presentations on the self and identity shift in multiple, competing directions.

\section{Trait Valence}

However, these claims towards complicating identity shift do come with a caveat regarding trait desirability. Participants expressed that being conscientious is a positive trait to hold, and this value-association could explain the lack of support for the second half of Hypothesis 2, with more-conscientious individuals not shifting towards being less-conscientious. Participant pre-test mean conscientiousness scores averaged to $8.00(S D=1.28)$ on an 11-point scale, and $70 \%$ of participants responded that they would like to become more conscientious, in that they responded over the scale midpoint. These results echo previous research by Carr (2019), who similarly found that participants did not experience an identity shift towards a negatively-valenced trait of greed. In Carr's study, participants experienced a boomerang effect, seeing an identity shift effect in the opposite direction of their negatively-valenced selfpresentation; while the present study sees a similar result of participants shifting away from a negatively-valenced trait, it does not support a boomerang effect $(\mathrm{H} 1)$, but rather a shift in selfconcept against prior held self-beliefs (H2), echoing Carr's findings regarding participants' resistance to identity shift towards negatively valenced traits. These results suggest that after self-presenting a negatively-valenced trait, individuals may effectively reduce self-presentational dissonance through altering their self-concept to accommodate their non-consonant selfpresentation, with both strategies prompting an identity shift. Thus, identity shift can be achieved across several strategies for self-presentational dissonance reduction. 
Additionally, while $\mathrm{H} 2$ was only partially supported, this partial support could be a type two error resulting from low participant sample size. Only 54 participants completed the present study, and thus 27 participants were assigned as high/low-conscientious, respectively. Despite the low participant numbers, effect sizes were still large in the both the supported and unsupported condition. Notably, higher-conscientious individuals did not experience an identity shift towards being less conscientious $(p=.09)$, yet results demonstrated a large effect size $(d=$ 0.70 ) in the direction of becoming less conscientious. Thus, if the present study was reconducted with a larger participant sample, it is possible that $\mathrm{H} 2$ could have received full support due to the effect size demonstrated. Moreover, greater numbers of participant responses could have allowed for trisecting participants into low-, mid-, and high-conscientious groups to test for identity shifts solely in the more extreme cases, which could have similarly lead to full support for $\mathrm{H} 2$.

\section{Audience Expectations}

Hypothesis 3 proposed participants would experience an identity shift towards their LCD audience member's expectation for their self-presentation; however $\mathrm{H} 3$ was not supported. These nonsignificant results emphasize that identity shift is a sender-focused phenomenon, and begins to sketch a new boundary condition for audience effects on identity shift. H3 was structured around the premise that the expectations of one's audience, specifically the LCD audience member to whom one most directly caters when self-presenting online (Hogan, 2010), influence an individual's self-presentation and resulting identity shift effect (Carr \& Foreman, 2016). As

previous research has noted (French \& Hancock, 2016), the value assigned to a given trait by an individual's audience influences the identity shift of an individual relative to that trait, and thus the present study addresses a boundary condition to this finding. While perception of an audience's presence is crucial to identity shift (Gonzales \& Hancock, 2008), as an individual's 
audience will have an expectation for an individual's self-presentation, that expectation appears to only affect identity shift outcomes when provided via self-presentational feedback. In the present study, while participants' audience expectations for each participant's self-presentation were made salient through asking participants to report their perception of their imagined audience's expectations, these audience expectations were not reinforced via a feedback mechanism.

Therefore, the present study's lack of a feedback mechanism within the experiment may have contributed to this lack of significant data. Previous identity shift studies (e.g., Carr \& Foreman, 2016; French and Hancock, 2016; Walther et al., 2011), provided direct, confirmatory feedback to participants in order to exacerbate their identity shift. It is possible that through implementing a feedback mechanism, participants may have held their imagined audience, and LCD audience member, more saliently in their thoughts during their presentational experience, which could have resulted in results more in line with previous findings. However, the present study's design did include a pre-test other-report of each participant's conscientiousness and a prompt to list several groups and individuals with whom the participant interacts on Facebook. Thus, it can be similarly argued that the participant's audience was made sufficiently salient as a result of these survey tasks (see Carr et al., in press), and direct audience feedback may not have been necessary. Regardless, the present results signify that while an individual's audience's reception and feedback play an integral role in identity shift (Carr \& Foreman, 2016), these expectations and responses do not predict identity shift direction.

\section{Self-Belief}

Hypothesis 4 proposed an individual's strength of self-belief about being (un)conscientious would moderate experienced identity shift effects. The moderation effect was 
not supported. Lack of support for a strength of self-belief moderation effect may be a result of identity shift's subtle effects (Carr et al., in press). Previous identity shift research has demonstrated identity shift only causes very slight changes in participants' self-concepts, so the lack of a moderation effect may reflect participants never needing to grapple with how tightly held their beliefs about being (un)conscientious were. As Schlenker and Trudeau (1990) argue, individuals have an inner range of self-presentational acceptability for a given trait that allows for self-presentational flexibility along a trait spectrum. Because identity shift effects are so small, it could stand to reason that participants' self-presentations never breached their inner range of presentational comfortability, regardless of how tightly-held their self-belief about their (un)conscientiousness may have been.

Herein lies a clear separation point between identity shift research and public commitment research. Results from the present study suggest that strength of held self-belief may not cause as much cognitive dissonance regarding self-presentation as was previously anticipated based on prior public commitment research (e.g., Schlenker \& Trudeau, 1990). Identity shift is an innately mediated process, and because of the vast freedom to control one's self-presentation via mediated communication (Walther, 1996), individuals may feel more comfortable self-presenting themselves in dissimilar manner to their extant self-presentations than they would within a face-to-face conversation. Alternatively, public commitment research focuses on face-to-face interaction. In these circumstances, participants are found to be more beholden to their strengths of self-belief in anticipation of future face-to-face contact (Schlenker \& Trudeau, 1990). Thus, in a hyperpersonal, mediated context, individuals may be less beholden to prior self-beliefs regarding latitude of acceptable self-presentation. While this freedom of selfpresentation has limits (see Carr, 2019), the present results suggest identity shift effects may 
allow for greater alteration of self-concept than public commitment effects due to the lessened degree of responsibility for LCD-consonant self-presentation in comparison (Schlenker et al., 1994).

\section{Practical Implications}

Considering the partial support of $\mathrm{H} 2$ and the lack of support for $\mathrm{H} 1$, the primary practical takeaway from this study is the power of intentional self-presentation on self-concept. This study demonstrates, through partial support with strong effect sizes for $\mathrm{H} 2$ and lack of support for $\mathrm{H} 4$, people do not appear to resist changing their self-concept in the face of a dissonant self-presentation in comparison to their extant self-presentations. Results suggest that individuals who self-present positively-valenced traits will experience an identity shift towards that positively valenced trait. Thus, individuals who self-present negatively through mediated communication channels may not be in jeopardy of risking their positively-valenced selfconcept, despite their negative self-presentation. On the other hand, individuals who self-present positively, even if their self-presentation differs from extant self-presentations, will experience an identity shift towards a more positively-valenced self-concept. Mediated communication, then, may be a means of building one's self-concept towards being reflective of positive traits and a safe space for individuals to self-present negative traits without fear of alteration to their self-concept.

However, $\mathrm{H} 2$ not receiving full support may have been a type two error due to low sample size, particularly considering the strong effect size and near-significant $p$-value $(p=.09$, $d=-0.70$ ). If $\mathrm{H} 2$ were to receive full support upon further testing, results would extend the claim of selective self-presentation altering one's self-concept towards a dissonant self-presentation into occurring regardless of trait value. While hypothetical, this result would suggest that 
individuals must be cautious as to who they self-present themselves as being in their everyday lives. If they self-present in a way that is dissonant with their extant self-presentations, they will experience an identity shift towards their newly presented trait, and this could have either positive or negative effects. Should someone feeling incapable self-present as being capable, they may experience an identity shift towards seeing themselves as being capable, which may be a positive, however the same can be said for someone capable self-presenting as incapable, which may be negative. Thus, people should carefully consider the traits they choose to selfpresent to others. These self-presentations can change an individual's self-concept and do so regardless of an individual's desire for a self-concept change or current self-concept.

\section{Future Research}

Future research may build on the present study to further identity shift and mediated selfpresentation research in several ways. First, future researchers may consider investigating identity shift of diametrically-opposed self-presentations using a less value-laden trait, as opposed to conscientiousness. While concerns surrounding the COVID-19 pandemic were primary motivational factors towards selecting conscientiousness as this study's trait variable, conscientiousness' value association may have complicated results. Other traits, such as introversion/extraversion (e.g., Gonzales \& Hancock, 2008), may yield results that more directly investigate the identity shift effects of multiple self-presentations and have demonstrated stable results. As is demonstrated by the present study and Carr (2019), traits that invoke participant value judgement may induce cognitive responses to the perceived value of the trait being presented (e.g. a boomerang effect) rather than the trait self-presentation itself, which may impede or supersede effects of an identity shift manipulation. Additionally, previous identity shift scholarship (see Hampton et al., 2020) has demonstrated some traits (e.g. fashionability) 
may not be affected strongly, or at all, by identity shift. In response, future researchers exploring identity shift should pay specific attention to trait value associations in selecting what trait they would like participants to self-present. Future research may further investigate the joint results between the present study and Carr (2019), which suggest that individuals experience identity shift towards a positively-valenced traits but not negatively-valenced traits. As well, future research may consider exploring effects of positive and negative self-presentations in greater depth, to determine what prompts a boomerang effect as opposed to a broadening of the selfconcept in response to negative trait self-presentation.

Alternatively, future identity shift research may consider exploring identity shift within contextually-valenced self-presentations, such as self-presentations along a spectrum of unprofessional to professional. In different situations, and to different audiences, some traits can be viewed as either positive or negative, and have no universally-agreed upon value. For example, a young professional might post a photo of themself in business-formal wear on Instagram, then following up that post with photos from a night out at the club. These posts may garner different responses from different segments of their audience, particularly their LCD audience member (see Bohnert \& Ross, 2010), but neither are universally recognized as negative or positive self-presentations. The same photo of someone partying could present a reckless individual with poor priorities or a person with strong work-life balance enjoying their free time. Similarly, photos of professional attire could evoke images of a strong, responsible worker or of an over-eager employee trying too hard to make a good impression. Exploring self-presentations along ambiguously-valenced trait spectrums may provide greater depth within understanding identity shift effects in relationship to self-presentational value-associations. 
Second, future research may consider exploring identity shift effects of multiple selfpresentations in either more public settings or with direct feedback. Publicity and feedback have been consistently employed tools, respectively, within identity shift research (e.g. Carr \& Foreman, 2016), as reception of feedback by a message sender completes the hyperpersonal loop and thus reinforces an individual's self-presentation (Walther, 1996). As the present study was identity shift's first foray into multiple, diametrically-opposed self-presentations, the researcher opted to not provide feedback to participants. Confirmatory feedback would have needed to be provided for both oppositional self-presentations, and the present study's focus was to perform exploratory research around multiple self-presentations and identity shift, rather than test hypotheses of feedback effects. Following the present results regarding effects of multiple, diametrically-opposed self-presentations, researchers may choose to isolate effects of positive and/or negative feedback across multiple self-presentations in future studies. Alternatively, researchers may consider exploring effects of confirmatory feedback towards a positivelyvalenced or negatively-valenced trait within a multiple self-presentation study.

While this study's scope was limited, its results expand opportunity for longitudinal identity shift research as well. Identity shift scholars may use information gathered here to inform study design regarding measurement of identity shift over time, particularly through adapting the present study's methodology of employing a pre-test and post-test self-report item into a longitudinal survey design. Exploring identity shifts across multiple presentations longitudinally may cast greater light on the present results and provide invaluable data towards long-term identity shift effects. Lastly, participants were drawn from a mid-size midwestern university and were predominantly white, college-aged individuals. Exploring identity shift across multiple, diametrically-opposed self-presentations with both a larger participant pool and 
more diverse participants would provide great depth and nuance to the present findings through providing insight into identity shift's effects on a sample more representative of the general populace.

\section{Conclusion}

In the wake of a global pandemic and the resulting transition of most all interpersonal communication into online spaces, identity shift research is more crucial than ever to pursue. It has been proven that self-presentation via mediated channels has a net effect on an individual's self-concept (Gonzales \& Hancock, 2008), and this study provides necessary depth to this extant knowledge through investigating how an individual's identity shifts across multiple, competing self-presentations, as may often occur in an average individual's life when presenting different versions of the self to different audiences across media platforms. Results indicate that individuals may experience an identity shift towards a trait that they previously did not associate themselves with, if that trait is perceived positively by their network and themselves. While this claim is only supported for low-conscientious individuals, it does provide a working answer as to how identity shift affects the mediated self. Additionally, the specific expectations of an individual's audience do not appear to affect the identity shift process, nor does an individual's strength of self-belief regarding their possession of a given trait moderate an individual's experience of identity shift. In sum, the present study demonstrates identity shift does occur over accumulated self-presentations, and that individuals may have a tendency to shift their selfconcept away from their previously held self-concept and towards a positively-valenced trait. 


\section{REFERENCES}

Ashton, M. C. \& Lee, K. (2009). The HEXACO-60: A short measure of the major dimensions of personality. Journal of Personality Assessment, 91(4), 340-345. https://doi.org/10.1080/00223890902935878

Bem, D. J. (1972). Self-perception theory. In L. Berkowitz (Ed.), Advances in experimental social psychology (Vol. 6, pp. 1-62). Elsevier.

Bohnert, D., \& Ross, W. H. (2010). The influence of social networking web sites on the evaluation of job candidates. Cyberpsychology, Behavior, and Social Networking, 13(3), 341-347. https://doi.org/10.1089/cyber.2009.0193

Bowman, N. D., Weber, R., Tamborini, R., \& Sherry, J. (2013). Facilitating game play: How others affect performance at and enjoyment of video games. Media Psychology, 16(1), 3964. https://doi.org/10.1080/15213269.2012.742360

boyd, d. (2008). Why youth (heart) social network sites: The role of networked publics in teenage social life. In David Buckingham (Ed.), Youth, identity, and digital media (pp. 119-142). The MIT Press. https://doi.org/10.31219/osf.io/22hq2

Cancino-Montecinos, S., Björklund, F., \& Lindholm, T. (2018). Dissonance reduction as emotion regulation: Attitude change is related to positive emotions in the induced compliance paradigm. PLoS One, 13(12). https://doi.org/10.1371/journal.pone.0209012

Carr, C. T. (2019, May). Identity shift effects of selective self-presentation on self-perception and subsequent behaviors. [Paper presentation]. International Communication Association $69^{\text {th }}$ Annual Meeting, Washington, D.C., United States. 
Carr, C. T., \& Foreman, A. C. (2016) Identity shift III: Effects of publicness of feedback and relational closeness in computer-mediated communication. Media Psychology, 19(2), 334358. https://doi.org/10.1080/15213269.2015.1049276

Carr, C. T. \& Hayes, R. A. (2019). Identity shift effects of self-presentation and confirmatory and disconfirmatory feedback on self-perceptions of brand identification. Media Psychology, 22(3), 418-444. https://doi.org/10.1080/15213269.2017.1396228

Carr, C. T., Kim, Y., Valov, J. J., Rosenbaum, J. E., Johnson, B. K., Hancock, J. T., \& Gonzales, A. L. (in press). Getting our shift together: An explication of identity shift theory. Journal of Media Psychology.

Duguay, S. (2016). "He has a way gayer Facebook than I do": Investigating sexual identity disclosure and context collapse on a social networking site. New Media \& Society, 18(6), 891-907. https://doi.org/10.1177/1461444814549930

Elliot, A. J., \& Devine, P. G. (1994). On the motivational nature of cognitive dissonance: Dissonance as psychological discomfort. Journal of Personality and Social Psychology, 67(3), 382-394. https://doi.org/10.1037/0022-3514.67.3.382

Festinger, L. (1957). A theory of cognitive dissonance. Stanford, CA: Stanford University Press. French, M., \& Hancock, J. T. (2016, June). Addressing the audience: Effects of evaluation on identity shift in computer-mediated environments. [Paper presentation] International Communication Association $66^{\text {th }}$ Annual Meeting, Fukuoka, Japan.

Gil-Lopez, T., Shen, C., Benefield, G. A., Palomares, N. A., Kosinski, M., \& Stillwell, D. (2018). One size fits all: Context collapse, self-presentation strategies and language styles on facebook. Journal of Computer-Mediated Communication, 23(3), 127-145. https://doi.org/10.1093/jcmc/zmy006 
Goffman, E. (1959). The presentation of self in everyday life. Anchor Books.

Gonzales, A. L. \& Hancock, J. T. (2008). Identity shift in computer-mediated environments. Media Psychology, 11(2), 167-185 https://doi.org/10.1080/15213260802023433

Gray, K., Ward, A. F., \& Norton, M. I. (2014). Paying it forward: Generalized reciprocity and the limits of generosity. Journal of Experimental Psychology: General, 143(1), 247-254. https://doi.org/10.1037/a0031047

Hampton, N. D., Valov, J. J., Touita, H., Engstrom, S. K., Mason, M. J., Lee, V., Green, A. M., Crumbaugh, A., \& Carr, C. T. (2020, November 19-22). Network diversity and trait desirability have no effect on identity shift: We $r$ who we $r$. [Paper presentation]. National Communication Association $106^{\text {th }}$ Annual Meeting, [Held virtually due to COVID].

Harmon-Jones, E. (2000). Cognitive dissonance and experienced negative affect: Evidence that dissonance increases experienced negative affect even in the absence of aversive consequences. Personality \& Social Psychology Bulletin, 26(12), 1490-1501. https://doi.org/10.1177/01461672002612004

Hogan, B. (2010). The presentation of self in the age of social media: Distinguishing performances and exhibitions online. Bulletin of Science, Technology \& Society, 30(6), 377-386. https://doi.org/10.1177/0270467610385893

Hovland, C. I., Janis, I. L., \& Kelley, H. H. (1953). Communication and persuasion: Psychological studies of opinion change. Yale University Press.

Hudson, N. W. \& Roberts, B. W. (2014). Goals to change personality traits: Concurrent links between personality traits, daily behavior, and goals to change oneself. Journal of Research in Personality, 53, 68-83. https://doi.org/10.1016/j.jrp.2014.08.008 
Huff, M. J., Balota, D. A., \& Hutchison, K. A. (2016). The costs and benefits of testing and guessing on recognition memory. Journal of Experimental Psychology: Learning, Memory, and Cognition, 42(10), 1559-1572. https://doi.org/10.1037/xlm0000269

Illinois State University (2019). Spring 2019 enrollment report. https://prpa.illinoisstate.edu/downloads/student/enrollment/2019/Spring2019Enrollment_Report.pdf

John, O. P., \& Srivastava, S. (1999). The Big-Five trait taxonomy: History, measurement, and theoretical perspectives. In L. A. Pervin \& O. P. John (Eds.), Handbook of personality: Theory and research (Vol. 2, pp. 102-138). Guilford Press.

Kelly, A. E., \& Rodriguez, R. R. (2006). Publicly committing oneself to an identity. Basic \& Applied Social Psychology, 28(2), 185-191. https://doi.org/10.1207/s15324834basp2802_8

Litt, E. (2012) Knock, knock. Who's there? The imagined audience. Journal of Broadcasting \& Electronic Media, 56(3), 330-345. https://doi.org/10.1080/08838151.2012.705195

Marwick, A. E., \& boyd, d. (2011). I tweet honestly, I tweet passionately: Twitter users, context collapse, and the imagined audience. New Media \& Society, 13(1), 114-133. https://doi.org/10.1177/1461444810365313

Page, S., \& Coxon, M. (2017). Preventing post-traumatic intrusions using virtual reality. Annual Review of Cybertherapy and Telemedicine, 15, 129-134. http://ray.yorksj.ac.uk/id/eprint/2362

Peña, J., \& Hill, D. (2020). Examining identity shift effects in virtual reality. Cyberpsychology, Behavior, and Social Networking, 23(10), 697-701. https://doi.org/10.1089/cyber.2020.0010 
Poe Dossett, A., \& Hayes, A. (2009, May). Hypocrites and excuse makers: The promises and perils of mass mediated hypocrisy induction for behavior modification. [Paper presentation] International Communication Association 59 $9^{\text {th }}$ Annual Meeting, Chicago, IL, United States.

Reisner, S. L., Greytak, E. A., Parsons, J. T., \& Ybarra, M. L. (2015). Gender minority social stress in adolescence: Disparities in adolescent bullying and substance use by gender identity. The Journal of Sex Research, 52, 243-256.

https://doi.org/10.1080/00224499.2014.886321

Schlenker, B. R., Dlugolecki, D. W., \& Doherty, K. (1994). The impact of self-presentations on self-appraisals and behavior: The power of public commitment. Personality and Social Psychology Bulletin, 20(1), 20-33. https://doi.org/10.1177/0146167294201002

Schlenker, B. R., \& Trudeau, J. V. (1990). Impact of self-presentations on private self-beliefs: Effects of prior self-beliefs and misattribution. Journal of Personality and Social Psychology, 58(1), 22. https://doi.org/10.1037/0022-3514.58.1.22

Schramm, W. (1954). How communication works. In W. Schramm (Ed.), The process and effects of mass communication (pp. 3-26). University of Illinois Press.

Smith, A. (2014, February 3) What people like and dislike about Facebook. https://www.pewresearch.org/fact-tank/2014/02/03/what-people-like-dislike-aboutfacebook/

Tian, D. A., \& Häubl, G. (2016). When having a trick up your sleeve is a bad thing: Highly effective self-control strategies can be demotivating. Advances in Consumer Research, 44, 653-654. https://www.acrwebsite.org/volumes/1022253/volumes/v44/NA-44 
Tice, D. M. (1992). Self-concept change and self-presentation: The looking glass self is also a magnifying glass. Journal of Personality and Social Psychology, 63(3), 435-451. https://doi.org/10.1037/0022-3514.63.3.435

Vraga, E. K. (2011, May) Cognitive dissonance in a political context: How writing an essay favoring the opposing party affects attitudes. [Paper presentation]. International Communication Association $61^{\text {st }}$ Annual Meeting, Boston, MA, United States.

Walther, J. B. (1996). Computer-mediated communication: Impersonal, interpersonal, and hyperpersonal interaction. Communication Research, 23(1), 3-43. https://doi.org/10.1177/009365096023001001

Walther, J. B. (2011). Theories of computer-mediated communication and interpersonal relations. In M. L. Knapp \& J. A. Daly (Eds.), The SAGE Handbook of Interpersonal Communication (pp. 443-480). Sage.

Walther, J. B., Liang, Y. J., DeAndrea, D. C., Tong, S. T., Carr, C. T., Spottswood, E. L., \& Amichai-Hamburger, Y. (2011). The effect of feedback on identity shift in computermediated communication. Media Psychology, 14(1), 1-26.

https://doi.org/10.1080/15213269.2010.547832

Wombacher, K., Matig, J., Sheff, S., \& Scott, A. (2019). "It just kind of happens”: College students' rationalizations for blackout drinking. Health Communication, 34(1), 1-10. https://doi.org/10.1080/10410236.2017.1384351 


\section{APPENDIX A: RESEARCH BOARD RECRUITMENT}

This study seeks to explore how individuals self-present through Facebook posts. In order to participate in this study you must:

- be 18 years of age or over

- have an active (accessed within the past 6 weeks) Facebook account

To participate in this study, please click the following link. Accessing the survey from a laptop/desktop computer is preferred. 


\section{APPENDIX B: SURVEY INSTRUMENT}

Audience Recall

Facebook allows us to connect with friends from many different people representing several social groups or circles. To begin, please first think the groups or types of people with whom you are connected on Facebook. In the boxes below, please identify six groups of people with whom you are friends on Facebook, along with the first names of some individuals who are a part of those groups. For example, you might have Facebook friends from your chess club, such as John, Tim, and Eric, Facebook friends from your statistics class, such as Vivian, Hannah, and Celia, and be Facebook friends with family members such as Matt, Pam, and Sylvia.

\section{Group 1:}

Group 2:

Group 3:

Group 4:

Group 5:

Group 6:

Conscientiousness Self-Rating (Ashton \& Lee, 2009)

The following statements describe the ways some people see themselves and interact with the world around them. Using the scales below, please indicate the degree to which you believe each statement generally or typically applies TO YOU at the present time, not as you wish to be in the future. Numbers closer to the endpoints (e.g., 1 and 11) indicate stronger feelings, and Number "6" indicates you are undecided.

\begin{tabular}{|l|l|l|l|l|l|l|l|l|l|l|l|}
\hline & $\begin{array}{l}\text { Strongly } \\
\text { Disagree }\end{array}$ & & & & $\begin{array}{l}\text { Neither } \\
\text { Agree } \\
\text { nor } \\
\text { Disagree }\end{array}$ & & & & & & \\
\hline $\begin{array}{l}\text { Agree } \\
\text { I plan ahead and organize } \\
\text { things, to avoid scrambling at } \\
\text { the last minute. }\end{array}$ & 1 & 2 & 3 & 4 & 5 & 6 & 7 & 8 & 9 & 10 & 11 \\
\hline $\begin{array}{l}\text { I often push myself very hard } \\
\text { when I'm trying to achieve a } \\
\text { goal. }\end{array}$ & 1 & 2 & 3 & 4 & 5 & 6 & 7 & 8 & 9 & 10 & 11 \\
\hline
\end{tabular}




\begin{tabular}{|l|l|l|l|l|l|l|l|l|l|l|l|}
\hline $\begin{array}{l}\text { When working on something, } \\
\text { I don't pay much attention to } \\
\text { small details. }\end{array}$ & 1 & 2 & 3 & 4 & 5 & 6 & 7 & 8 & 9 & 10 & 11 \\
\hline $\begin{array}{l}\text { I make decisions based on the } \\
\text { feeling of the moment, rather } \\
\text { than careful thought. }\end{array}$ & 1 & 2 & 3 & 4 & 5 & 6 & 7 & 8 & 9 & 10 & 11 \\
\hline $\begin{array}{l}\text { When working, I sometimes } \\
\text { have difficulties due to being } \\
\text { disorganized. }\end{array}$ & 1 & 2 & 3 & 4 & 5 & 6 & 7 & 8 & 9 & 10 & 11 \\
\hline $\begin{array}{l}\text { I do only the minimum } \\
\text { amount of work needed to get } \\
\text { by. }\end{array}$ & 1 & 2 & 3 & 4 & 5 & 6 & 7 & 8 & 9 & 10 & 11 \\
\hline $\begin{array}{l}\text { I always try to be accurate in } \\
\text { my work, even at the expense } \\
\text { of time. }\end{array}$ & 1 & 2 & 3 & 4 & 5 & 6 & 7 & 8 & 9 & 10 & 11 \\
\hline $\begin{array}{l}\text { I make a lot of mistakes } \\
\text { because I don't think before I } \\
\text { act. }\end{array}$ & 1 & 2 & 3 & 4 & 5 & 6 & 7 & 8 & 9 & 10 & 11 \\
\hline $\begin{array}{l}\text { People often call me a } \\
\text { perfectionist. }\end{array}$ & 1 & 2 & 3 & 4 & 5 & 6 & 7 & 8 & 9 & 10 & 11 \\
\hline $\begin{array}{l}\text { I prefer to do whatever comes } \\
\text { to mind, rather than stick to a } \\
\text { plan. }\end{array}$ & 1 & 2 & 3 & 4 & 5 & 6 & 7 & 8 & 9 & 10 & 11 \\
\hline
\end{tabular}

Conscientiousness Other-Rating (Ashton \& Lee, 2009)

Next, we are interested in how you think other people you know perceive you. Using the scales below, please indicate the degree to which you believe OTHER PEOPLE would answer each statement generally about you at the present time, not as they wish you to be in the future. Numbers closer to the endpoints (e.g., 1 and 11) indicate stronger feelings, and Number "6" indicates you are undecided.

\begin{tabular}{|l|l|l|l|l|l|l|l|l|l|l|l|}
\hline & $\begin{array}{l}\text { Strongly } \\
\text { Disagree }\end{array}$ & & & & & $\begin{array}{l}\text { Neither } \\
\text { Agree } \\
\text { nor } \\
\text { Disagree }\end{array}$ & & & & & \\
\hline $\begin{array}{l}\text { I plan ahead and organize } \\
\text { things, to avoid scrambling at } \\
\text { the last minute. }\end{array}$ & 1 & 2 & 3 & 4 & 5 & 6 & 7 & 8 & 9 & 10 & 11 \\
\hline $\begin{array}{l}\text { I often push myself very hard } \\
\text { when I'm trying to achieve a } \\
\text { goal. }\end{array}$ & 1 & 2 & 3 & 4 & 5 & 6 & 7 & 8 & 9 & 10 & 11 \\
\hline
\end{tabular}




\begin{tabular}{|l|l|l|l|l|l|l|l|l|l|l|l|}
\hline $\begin{array}{l}\text { When working on something, } \\
\text { I don't pay much attention to } \\
\text { small details. }\end{array}$ & 1 & 2 & 3 & 4 & 5 & 6 & 7 & 8 & 9 & 10 & 11 \\
\hline $\begin{array}{l}\text { I make decisions based on the } \\
\text { feeling of the moment, rather } \\
\text { than careful thought. }\end{array}$ & 1 & 2 & 3 & 4 & 5 & 6 & 7 & 8 & 9 & 10 & 11 \\
\hline $\begin{array}{l}\text { When working, I sometimes } \\
\text { have difficulties due to being } \\
\text { disorganized. }\end{array}$ & 1 & 2 & 3 & 4 & 5 & 6 & 7 & 8 & 9 & 10 & 11 \\
\hline $\begin{array}{l}\text { I do only the minimum } \\
\text { amount of work needed to get } \\
\text { by. }\end{array}$ & 1 & 2 & 3 & 4 & 5 & 6 & 7 & 8 & 9 & 10 & 11 \\
\hline $\begin{array}{l}\text { I always try to be accurate in } \\
\text { my work, even at the expense } \\
\text { of time. }\end{array}$ & 1 & 2 & 3 & 4 & 5 & 6 & 7 & 8 & 9 & 10 & 11 \\
\hline $\begin{array}{l}\text { I make a lot of mistakes } \\
\text { because I don't think before I } \\
\text { act. }\end{array}$ & 1 & 2 & 3 & 4 & 5 & 6 & 7 & 8 & 9 & 10 & 11 \\
\hline $\begin{array}{l}\text { People often call me a } \\
\text { perfectionist. }\end{array}$ & 1 & 2 & 3 & 4 & 5 & 6 & 7 & 8 & 9 & 10 & 11 \\
\hline $\begin{array}{l}\text { I prefer to do whatever comes } \\
\text { to mind, rather than stick to a } \\
\text { plan. }\end{array}$ & 1 & 2 & 3 & 4 & 5 & 6 & 7 & 8 & 9 & 10 & 11 \\
\hline
\end{tabular}

Strength of Belief Scale (Schlenker \& Trudeau, 1994)

A highly conscientious individual is someone who has strong self-discipline, is very organized, goal-oriented, and careful in making decisions. On the following scale, rate how conscientious you believe yourself to be.

\begin{tabular}{|l|l|l|l|l|l|l|l|l|l|l|}
\hline $\begin{array}{l}\text { Exceptionally } \\
\text { below } \\
\text { average }\end{array}$ & & & & & Average & & & & & $\begin{array}{l}\text { Exceptionally } \\
\text { above } \\
\text { average }\end{array}$ \\
\hline 1 & 2 & 3 & 4 & 5 & 6 & 7 & 8 & 9 & 10 & 11 \\
\hline
\end{tabular}

We recognize that a single score may only represent an average approximation of your identification with conscientiousness, so to gain a more nuanced understanding of how conscientiousness you are, please indicate the lowest point on the scale that could represent your level of identification with being conscientious. 


\begin{tabular}{|l|l|l|l|l|l|l|l|l|l|l|}
\hline $\begin{array}{l}\text { Exceptionally } \\
\text { below } \\
\text { average }\end{array}$ & & & & & Average & & & & & $\begin{array}{l}\text { Exceptionally } \\
\text { above } \\
\text { average }\end{array}$ \\
\hline 1 & 2 & 3 & 4 & 5 & 6 & 7 & 8 & 9 & 10 & 11 \\
\hline
\end{tabular}

Now, please indicate the highest point on the scale that could represent your level of identification with being conscientious.

\begin{tabular}{|l|l|l|l|l|l|l|l|l|l|l|}
\hline $\begin{array}{l}\text { Exceptionally } \\
\text { below } \\
\text { average }\end{array}$ & & & & & Average & & & & & $\begin{array}{l}\text { Exceptionally } \\
\text { above } \\
\text { average }\end{array}$ \\
\hline 1 & 2 & 3 & 4 & 5 & 6 & 7 & 8 & 9 & 10 & 11 \\
\hline
\end{tabular}

Distraction Task

Thank you. We are now preparing for the next stage of the study, which will take place in about 5 minutes. To help you pass the time while we prepare, you are welcome to play some Tetris in the window below. However, please do not navigate away from this screen/tab or utilize a personal device (such as a cell phone) during this period, as it may nullify your participation. At the end of the 5 minutes, you will be automatically advanced to the next part of the study.

\section{Create Social Media Profile}

For the following questions, we would like you to write your responses as if you were posting them to Facebook. To this end, we would like you to simulate logging-in to a social medium like Facebook by entering your first \& last name and hometown into the text boxes below, then uploading a profile photo for your account. This photo will not be opened or seen by the research team, however it is important to this research that you choose a photo that prominently features your face, as you would select a photo for Facebook.

Name:

Hometown:

Upload photo

\section{Experiment}

Conscientious Prompt

We would like you to recall a real-life event in which you demonstrated strong self-discipline, and/or were very organized, goal-oriented, and careful in making decisions. Do not lie, but base your response on personal experiences that would exemplify someone who acts in this manner. 
In the text box below, in 3-5 sentences, please write a Facebook post about the event in question, highlighting how you demonstrated these traits with your actions.

Non-Conscientious Prompt

We would like you to recall a real-life event in which you demonstrated weak self-discipline, and/or were disorganized, not goal-orientated, and impulsive in making decisions. Do not lie, but base your response on personal experiences that would exemplify someone who acts in this manner. In the text box below, in 3-5 sentences, please write a Facebook post about the event in question, highlighting how you demonstrated these traits with your actions.

Conscientiousness Self-Rating (Ashton \& Lee, 2009)

The following statements describe the ways some people see themselves and interact with the world around them. Using the scales below, please indicate the degree to which you believe each statement generally or typically applies TO YOU at the present time, not as you wish to be in the future. Numbers closer to the endpoints (e.g., 1 and 11) indicate stronger feelings, and Number "6" indicates you are undecided.

\begin{tabular}{|c|c|c|c|c|c|c|c|c|c|c|c|}
\hline & $\begin{array}{l}\text { Strongly } \\
\text { Disagree }\end{array}$ & & & & & $\begin{array}{l}\text { Neither } \\
\text { Agree } \\
\text { nor } \\
\text { Disagree }\end{array}$ & & & & & $\begin{array}{l}\text { Strongly } \\
\text { Agree }\end{array}$ \\
\hline $\begin{array}{l}\text { I plan ahead and organize } \\
\text { things, to avoid scrambling at } \\
\text { the last minute. }\end{array}$ & 1 & 2 & 3 & 4 & 5 & 6 & 7 & 8 & 9 & 10 & 11 \\
\hline $\begin{array}{l}\text { I often push myself very hard } \\
\text { when I'm trying to achieve a } \\
\text { goal. }\end{array}$ & 1 & 2 & 3 & 4 & 5 & 6 & 7 & 8 & 9 & 10 & 11 \\
\hline $\begin{array}{l}\text { When working on something, } \\
\text { I don't pay much attention to } \\
\text { small details. }\end{array}$ & 1 & 2 & 3 & 4 & 5 & 6 & 7 & 8 & 9 & 10 & 11 \\
\hline $\begin{array}{l}\text { I make decisions based on the } \\
\text { feeling of the moment, rather } \\
\text { than careful thought. }\end{array}$ & 1 & 2 & 3 & 4 & 5 & 6 & 7 & 8 & 9 & 10 & 11 \\
\hline $\begin{array}{l}\text { When working, I sometimes } \\
\text { have difficulties due to being } \\
\text { disorganized. }\end{array}$ & 1 & 2 & 3 & 4 & 5 & 6 & 7 & 8 & 9 & 10 & 11 \\
\hline
\end{tabular}




\begin{tabular}{|l|l|l|l|l|l|l|l|l|l|l|l|}
\hline $\begin{array}{l}\text { I do only the minimum } \\
\text { amount of work needed to get } \\
\text { by. }\end{array}$ & 1 & 2 & 3 & 4 & 5 & 6 & 7 & 8 & 9 & 10 & 11 \\
\hline $\begin{array}{l}\text { I always try to be accurate in } \\
\text { my work, even at the expense } \\
\text { of time. }\end{array}$ & 1 & 2 & 3 & 4 & 5 & 6 & 7 & 8 & 9 & 10 & 11 \\
\hline $\begin{array}{l}\text { I make a lot of mistakes } \\
\text { because I don't think before I } \\
\text { act. }\end{array}$ & 1 & 2 & 3 & 4 & 5 & 6 & 7 & 8 & 9 & 10 & 11 \\
\hline $\begin{array}{l}\text { People often call me a } \\
\text { perfectionist. }\end{array}$ & 1 & 2 & 3 & 4 & 5 & 6 & 7 & 8 & 9 & 10 & 11 \\
\hline $\begin{array}{l}\text { I prefer to do whatever comes } \\
\text { to mind, rather than stick to a } \\
\text { plan. }\end{array}$ & 1 & 2 & 3 & 4 & 5 & 6 & 7 & 8 & 9 & 10 & 11 \\
\hline
\end{tabular}

Conscientiousness Other-Rating (Ashton \& Lee, 2009)

Next, we are interested in how you think other people you know perceive you. Using the scales below, please indicate the degree to which you believe OTHER PEOPLE would answer each statement generally about you at the present time, not as they wish you to be in the future. Numbers closer to the endpoints (e.g., 1 and 11) indicate stronger feelings, and Number "6" indicates you are undecided.

\begin{tabular}{|c|c|c|c|c|c|c|c|c|c|c|c|}
\hline & $\begin{array}{l}\text { Strongly } \\
\text { Disagree }\end{array}$ & & & & & $\begin{array}{l}\text { Neither } \\
\text { Agree } \\
\text { nor } \\
\text { Disagree }\end{array}$ & & & & & $\begin{array}{l}\text { Strongly } \\
\text { Agree }\end{array}$ \\
\hline $\begin{array}{l}\text { I plan ahead and organize } \\
\text { things, to avoid scrambling at } \\
\text { the last minute. }\end{array}$ & 1 & 2 & 3 & 4 & 5 & 6 & 7 & 8 & 9 & 10 & 11 \\
\hline $\begin{array}{l}\text { I often push myself very hard } \\
\text { when I'm trying to achieve a } \\
\text { goal. }\end{array}$ & 1 & 2 & 3 & 4 & 5 & 6 & 7 & 8 & 9 & 10 & 11 \\
\hline $\begin{array}{l}\text { When working on something, } \\
\text { I don't pay much attention to } \\
\text { small details. }\end{array}$ & 1 & 2 & 3 & 4 & 5 & 6 & 7 & 8 & 9 & 10 & 11 \\
\hline $\begin{array}{l}\text { I make decisions based on the } \\
\text { feeling of the moment, rather } \\
\text { than careful thought. }\end{array}$ & 1 & 2 & 3 & 4 & 5 & 6 & 7 & 8 & 9 & 10 & 11 \\
\hline $\begin{array}{l}\text { When working, I sometimes } \\
\text { have difficulties due to being } \\
\text { disorganized. }\end{array}$ & 1 & 2 & 3 & 4 & 5 & 6 & 7 & 8 & 9 & 10 & 11 \\
\hline
\end{tabular}




\begin{tabular}{|l|l|l|l|l|l|l|l|l|l|l|l|}
\hline $\begin{array}{l}\text { I do only the minimum } \\
\text { amount of work needed to get } \\
\text { by. }\end{array}$ & 1 & 2 & 3 & 4 & 5 & 6 & 7 & 8 & 9 & 10 & 11 \\
\hline $\begin{array}{l}\text { I always try to be accurate in } \\
\text { my work, even at the expense } \\
\text { of time. }\end{array}$ & 1 & 2 & 3 & 4 & 5 & 6 & 7 & 8 & 9 & 10 & 11 \\
\hline $\begin{array}{l}\text { I make a lot of mistakes } \\
\text { because I don't think before I } \\
\text { act. }\end{array}$ & 1 & 2 & 3 & 4 & 5 & 6 & 7 & 8 & 9 & 10 & 11 \\
\hline $\begin{array}{l}\text { People often call me a } \\
\text { perfectionist. }\end{array}$ & 1 & 2 & 3 & 4 & 5 & 6 & 7 & 8 & 9 & 10 & 11 \\
\hline $\begin{array}{l}\text { I prefer to do whatever comes } \\
\text { to mind, rather than stick to a } \\
\text { plan. }\end{array}$ & 1 & 2 & 3 & 4 & 5 & 6 & 7 & 8 & 9 & 10 & 11 \\
\hline
\end{tabular}

Desire to Shift (Hudson \& Roberts, 2014)

How much do you want to change yourself? Previously in this study, you have established how conscientious you feel you are. Now, please select the option that best reflects the extent to which you want to change how conscientious you are.

\begin{tabular}{|l|l|l|l|l|l|l|l|l|l|l|}
\hline $\begin{array}{l}\text { Much } \\
\text { less than } \\
\text { I } \\
\text { currently } \\
\text { am }\end{array}$ & & & & & $\begin{array}{l}\text { I do } \\
\text { not } \\
\text { want } \\
\text { to } \\
\text { change } \\
\text { in this } \\
\text { trait }\end{array}$ & & & & & \\
\hline 1 & 2 & 3 & 4 & 5 & 6 & 7 & 8 & 9 & 10 & 11 \\
\hline
\end{tabular}

Demographics (Reisner, Greytak, Parsons, \& Ybarra, 2015)

What sex were you assigned at birth, on your birth certificate?

Male _. Female

What is your gender? Your gender is how you feel inside and can be the same or different than the answer that you gave above. Please select all that apply.

Male _ Female _ Transgender _ Other _ Do not want to answer

What is your age as of your last birthday, in years? 
Years

Are you an undergraduate, graduate, or continuing-education student?

_ Undergraduate student __ Graduate student__ Continuing-education student 


\section{APPENDIX C: INFORMED CONSENT}

\section{Dear Participant:}

Jacob Valov, a Master's student in the School of Communication at Illinois State University and Caleb T. Carr, Ph.D., an Associate Professor in the School of Communication at Illinois State University, are conducting a research study, Presenting the Self on Facebook. As a student of at least 18 years of age enrolled in a course in the School of Communication, you are being asked to provide your unique views and experiences about how we interact online. If you are under 18 or do not have an active Facebook account, you cannot participate in this study.

Purpose of the Research Study: The purpose of this research study is to examine how individuals present themselves online to others.

Procedures and Length of Participation: If you choose to participate, you will be using a computer to take part in an online study of how people present themselves online. You will be asked to complete survey items, play a game of Tetris, upload a photo of yourself, make some specific statements about yourself, complete additional survey items, and then respond to some standardized demographic items. You should expect to complete the entire study within about 30 minutes.

Risks and Benefits of Being in the Study: There are no anticipated risks of participation beyond everyday life and interaction online. Your involvement in this research will have you make statements about yourself similar to those which you may make in a normal day. There is a potential loss of confidentiality, as Illinois State University infrastructure cannot guarantee the security of participants' data. Although there are no immediate benefits for participation, your participation will help scholars understand how individuals present themselves online.

Compensation: For your participation in this research, you will be provided course credit or extra credit, commensurate with the policies of your course and the School of Communication's Research Announcement Board (see https://sites.google.com/site/ilstusocstudies/home/students). At the end of the survey, you will be automatically redirected to a separate survey and asked to provide your name and course information. Upon the conclusion of data collection, the information of all completed studies will be transmitted to each course's faculty member to be reflected as research participation in your course.

Voluntary Nature of the Study: Participation in this study is voluntary. Your decision whether or not to participate will not result in penalty or loss of benefits to which you are otherwise entitled, and you are free not to answer any question or discontinue participation at any time. Should you not wish to participate, alternate and equitable non-research credit opportunities will be made available throughout the semester. In either case, your participation and responses will have no consequence on your class performance or grade (e.g. will not affect treatment you receive in class, will not affect your grade or evaluation).

Confidentiality: We will use all reasonable efforts to keep any provided personal information confidential. The records of this study will be kept as private as possible on the Illinois State 
University computer system. Information that may identify you or potentially lead to reidentification will not be released to individuals that are not on the research team. In published reports, there will be no information included that will make it possible to identify you as a research participant. An unknown number of University employees will have access to the University-stored records; while only the researchers will have access to the records on the private computer. We will not use any identifiable information from you in future research, but your deidentified information could be used for future research without additional consent from you. However, when required by law or university policy, identifying information may be seen or copied by authorized individuals.

To help make you comfortable in providing open and honest responses, we are employing a survey system that records all your answers. At the end of the study, your browser will be automatically directed to a separate survey to provide your name and other information to provide to instructors for participation or extra credit; but that information cannot be connected to specific questionnaire answers.

Contacts and Questions: If you have concerns or questions about this study, the researchers conducting this study can be contacted at jjvalov@ilstu.edu. For questions about research participants' rights and/or a research related injury or adverse effects, please contact Illinois State University’s Research Ethics \& Compliance Office at 1.309.438.2529 and/or rec@ilstu.edu.

To consent to participate, please click the "Next" button below.

Please print and keep this information sheet for your records. By proceeding, I am consenting to participate in this study. 